\title{
High-sensitivity determination of 2-chlorovinylarsonous acid in biomedical samples for retrospective detection of exposure to lewisite upon antidotal therapy
}

\author{
N.L. Koryagina a , E.S. Ukolova ${ }^{\text {a }}$, E.I. Savel'eva ${ }^{\text {a }}$, N.G. Voitenko ${ }^{\text {a }}$, O.I. Orlova ${ }^{\text {a }}$, \\ R.O. Jenkins ${ }^{b, *}$ and N.V. Goncharov ${ }^{a}$ \\ ${ }^{a}$ Research Institute of Hygiene, Occupational Pathology and Human Ecology, Saint Petersburg, Russia \\ ${ }^{\mathrm{b}}$ Faculty of Health and Life Sciences, De Montfort University, The Gateway, Leicester, UK
}

\begin{abstract}
A procedure for determination of the lewisite metabolite 2-chlorovinylarsonous acid (CVAA) in biomedical samples, involving derivatization of the latter with propane-1,3-dithiol and head-space solid-phase microextraction of the derivative on a 100- $\mu \mathrm{m}$ PDMS fiber followed by GC-MS, was applied for the first time to analysis of in vivo samples. The detection limits of CVAA in urine, plasma and red blood cells were $0.1,1.0$ and $10 \mathrm{ng} / \mathrm{ml}$, respectively. Upon exposure to lewisite at a dose of $1.6 \mathrm{mg} / \mathrm{kg}$, CVAA could be detected in rat urine for about three months. Study of the effect of a single injection of the antidote unithiol on the CVAA excretion profile revealed more active CVAA excretion during the first two days after the injection, compared to that observed in the absence of antidotal therapy.
\end{abstract}

Keywords: Lewisite, 2-chlorovinylarsonous acid, gas chromatography-mass spectrometry, biomedical samples, solid-phase microextraction, organoarsenic, monomethylarsonic acid

\section{Introduction}

Identification and quantification of chemical warfare agents (CWAs) and their metabolic products in biomedical samples is an essential component of the complex measures applied to verification of the implementation of the Chemical Weapons Convention (CWC) [4]. Intact CWAs are metabolized fairy rapidly in the human body and, therefore, the objects of retrospective detection of exposure to CWAs are their more stable hydrolysis products and protein adducts.

Unlike other CWAs, lewisite has not been a focus of researchers over the recent decades, even though tons of lewisite and mustard-lewisite mixtures are still buried in unknown places as old chemical weapons "left" after World War II.

Lewisite hydrolyses to form 2-chlorovinylarsonous acid (CVAA), which is the hydrated form of 2-chlorovinylarsine oxide and exists exclusively in aqueous solution. CVAA can be further oxidized

\footnotetext{
${ }^{*}$ Corresponding author: R.O. Jenkins, Faculty of Health and Life Sciences, De Montfort University, The Gateway, Leicester LE1 9BH, UK. E-mail: roj@dmu.ac.uk.
} 
to 2-chlorovinylarsonic acid (CVAOA). These two acids are lewisite markers, i.e., their detection in biomedical samples provides unequivocal evidence for exposure to lewisite. Vilensky et al. [11] suggested that CVAOA is the key marker of exposure to high doses of lewisite, whereas CVAA is primarily detected in biomedical samples on low-dose exposure. These two nonvolatile compounds are impossible to determine separately by GC. In our experience, the HPLC-MS/MS detection limit of CVAOA is at least an order of magnitude higher than that of CVAA, which casts some doubts on the interpretation of experimental data reported by Vilensky et al. [11]. In terms of detection of exposure of a human to lewisite, combined determination of CVAOA and CVAA in biomedical samples treated with a reducer is a reasonable approach, since both these compounds are absolute markers of lewisite. However, separate determination of CVAOA and CVAA is important for understanding the metabolism of lewisite and for developing schemes of antidotal therapy.

The action of most known high-efficiency lewisite antidotes is based on the reactions of the agent with sulfhydryl compounds, forming nontoxic derivatives. The first lewisite antidote 2,3-dimercapropropanol (British antilewisite, BAL) was suggested at the end of World War II [13]. New-generation antidotes, dithiosuccinic acid and sodium 2,3-dimercapto-1-propanesulfonate (unithiol), possess higher bioavailability and lower toxicity. Unithiol is included in first-aid kits used in toxicology emergency medicine and, in particular, is commonly used in treatment of acute arsenic poisonings [1-3]. In the case of real or suspected exposure to lewisite, antidotal therapy will be probably applied before biomedical samples will have been taken for analysis. Gong et al. [7] showed that antidotal therapy of lewisite poisonings enhances excretion of the agent and its redistribution from tissues to blood stream, which is bound to affect the results of analysis of lewisite markers in biomedical samples. Unithiol is considered to react with As(III) compounds to form a complex capable of being excreted rapidly from the human body within urine. However, this complex has never been detected.

We synthesize the CVAA complex with unithiol, but could not detect this complex in samples taken from laboratory animals exposed to lewisite by any of the instrumental techniques used (GC-MS, HPLCMS, MALDI-TOF). Although enhanced excretion of CVAA under the action of unithiol has been established [7], the chemical mechanism of this phenomenon is still unknown. In the present research we explored the possibility of determination of CVAA in the blood plasma, red blood cells and urine of animals after exposure to lewisite followed by antidotal therapy. The purpose of the research was to develop a procedure of analysis of CVAA in biomedical samples for detection of exposure to lewisite. The procedure was tested in a toxicological experiment in the presence and absence of antidotal therapy.

\section{Materials and methods}

Lewisite (State Standard Reference Sample (SSRS) 8245-2003); lewisite oxide (SSRS 8674-2005); propane-1,3-dithiol (CAS 109-80-8, Aldrich Cat.: P5,060-9, Lot.: S40625-028); phenylarsine oxide (PAO) (CAS 637-03-6, Aldrich Cat.: 40,249-4, Lot.: 71972-111); pharmacopeial unithiol (5\% aqueous solution); dimethyl sulfoxide, acetonitrile, methanol, sodium acetate, acetic acid, ascorbic acid, sodium citrate. All chemicals used were of analytical grade.

CVAA solutions were prepared by dissolving 2-chlorovinylarsine oxide in $0.6 \%$ aqueous ascorbic acid.

Buffer solutions at $\mathrm{pH} 4.5$ were prepared by mixing $37 \mathrm{ml}$ of $0.2 \mathrm{M}$ aqueous sodium acetate and $63.0 \mathrm{ml}$ of $0.2 \mathrm{M}$ aqueous acetic acid. 
Solid-phase microextraction (SPME) sampling stand (Supelco, Cat. No. 57333-U); polydimethylsiloxane $\left(\right.$ PDMS, $\left.d_{\mathrm{f}}=100 \mu \mathrm{m}\right)$ SPME fiber assembly (Supelco, Cat. No. 57300-U).

Three groups $(\mathrm{A}-\mathrm{C})$ of 12 white outbred rats with an average body weight of $270 \pm 24 \mathrm{~g}$ were used. Groups A and B were exposed to lewisite $(1.6 \mathrm{mg} / \mathrm{kg} \mathrm{sc})$; group B was also given a single injection of unithiol $(70 \mu \mathrm{l} / 100 \mathrm{~g}$ im) $30 \mathrm{~min}$ after exposure. Animals in group $\mathrm{C}$ (control) were given injections containing all auxiliary reagents but not containing lewisite or unithiol.

The stock solution of lewisite in DMSO $(c=10 \mathrm{mg} / \mathrm{ml})$ was prepared by adding $5.3 \mu$ of lewisite $\left(d_{4}^{25}=1.8793\right)$ into $1.0 \mathrm{ml}$ of DMSO; before use it was diluted with distilled water to a final concentration of $1.6 \mathrm{mg} / \mathrm{ml}$. The injection volume was calculated based on $100 \mu \mathrm{l}$ per $100 \mathrm{~g}$ body weight (on average, $300 \mu \mathrm{l}$ per animal). No deaths of animals were observed during the experiment.

Control rats were given a single subcutaneous injection of a mixture of distilled water with DMSO $(100 \mu \mathrm{l}$ per $100 \mathrm{~g}$ body weight). The animals were maintained in standard conditions in a vivarium and had free access to water and food, according to the European Convention for the Protection of Vertebrate Animals used for Experimental and Other Scientific Purposes [5].

Blood was taken under anesthesia (urethane, $1 \mathrm{~g} / \mathrm{kg}$ ) from the carotid artery. Sodium citrate, $3.8 \%$ aqueous solution, was used as anticoagulant (1 part of anticoagulant per 9 parts of blood; v/v). Whole blood was centrifuged at $2800 \mathrm{rpm}$ for $14 \mathrm{~min}$, plasma was withdrawn, transferred to a microtube, and frozen at $-70^{\circ}$. The remaining pellet of red blood cells was washed one time with saline solution and stored at $-70^{\circ}$ until analysis. Urine collection in the first week after exposure was performed using a water load of $5 \mathrm{ml}$ ip. In the second week urine collection was performed periodically without water loading. The overall time of the experiment was 77 days from the exposure.

\subsection{Gas chromatography-mass spectrometry $(G C-M S)$ analysis}

Phenylarsine oxide (PAO) was used as internal reference. The determination of CVAA and PAO as propane-1,3-dithiol (PDT) derivatives (CVAA-PDT and PAO-PDT, respectively) was performed by GC-MS on a Shimadzu QP 2010 instrument. The gas chromatograph was equipped with a DB-5 fused silica capillary column $(25 \mathrm{~m} \times 0.2 \mathrm{~mm}$, film thickness $0.32 \mu \mathrm{m})$ programmed from $90^{\circ} \mathrm{C}(1 \mathrm{~min})$ at $20^{\circ} \mathrm{C} / \mathrm{min}$ to $270^{\circ} \mathrm{C}(15 \mathrm{~min})$; carrier gas helium, flow rate $1 \mathrm{ml} / \mathrm{min}$. Injection mode splitless $(1 \mathrm{~min})$, injector temperature $250^{\circ} \mathrm{C}$; interface and detector temperatures 270 and $200^{\circ} \mathrm{C}$, respectively. The mass spectral conditions were as follows: ionization mode electron impact (EI); ionizing energy $70 \mathrm{eV}$; ion source temperature $200^{\circ} \mathrm{C}$; selected ion monitoring at $\mathrm{m} / \mathrm{z} 228,229$ for CVAA-PDT and 258, 259 for PAO-PDT. The m/z 228 and 258 ions were used for quantitation, and the m/z 229 and 259 ions were used for confirmation.

\section{Experimental section}

\subsection{Determination of CVAA in urine}

Urine, $1 \mathrm{ml}, 0.005 \mathrm{ml}$ of an acetonitrile solution of PAO with a concentration of $0.004 \mathrm{mg} / \mathrm{ml}$ (internal reference), and $25 \mu \mathrm{l}$ of an acetonitrile solution of propane-1,3-dithiol (1:10) were placed in 4-ml vial charged with $1.5 \mathrm{ml}$ of acetate buffer ( $\mathrm{pH} 4.5)$. The vial was closed with a cap with a teflon seal and heated for $20 \mathrm{~min}$ at $70^{\circ} \mathrm{C}$ with constant stirring. Analysis of CVAA was performed by head-space solidphase microextraction combined with GC-MS, using a 100- $\mu$ m PMDS microfiber. The microfiber was 
conditioned in a $\mathrm{GC}$ injector for $5 \mathrm{~min}$ at $280^{\circ} \mathrm{C}$ and then inserted into the vial by piercing the vial cap seal with the needle of the fiber holder and exposed to the vapor phase over the sample for 10 min under constant stirring at $70^{\circ} \mathrm{C}$. Thermodesorption of the analytes into the GC-MS system was performed under the conditions described above.

The linear range of the developed procedure is $0.1-20.0 \mathrm{ng} / \mathrm{ml}$; the linear regression equation is $y=$ $0.167 x(n=3)$, correlation coefficient $R^{2}=0.998$. Analysis time was $1 \mathrm{~h}$.

\subsection{Determination of CVAA in blood plasma}

Acetonitrile $(3 \mathrm{ml})$ was added to $1 \mathrm{ml}$ of blood plasma, and the mixture was shaken and centrifuged for $15 \mathrm{~min}$ at $12,000 \mathrm{rpm}$. The supernatant was reduced to dryness under nitrogen, and the dry residue was dissolved in $1.5 \mathrm{ml}$ of acetate buffer at $\mathrm{pH} 4.5$. Further workup was performed as described above.

The linear range of the developed procedure is $1.0-20.0 \mathrm{ng} / \mathrm{ml}$; the linear regression equation is $y=$ $0.0051 x(n=3)$, correlation coefficient $R^{2}=0.995$. Analysis time was $3 \mathrm{~h}$.

\subsection{Determination of CNAA in red blood cells}

The red blood cell mass obtained by centrifuging the whole blood was washed once with a saline solution at the $V_{\mathrm{rbs}}: V_{\text {saline }}$ ratio of 1:1, after which the equal volume of deionized water was added to the mass, and the mixture was incubated for $10 \mathrm{~min}$ at $4^{\circ} \mathrm{C}$ for hemolysis. The resulting hemolysate was diluted with two volumes of ice-cold methanol $\left(-20^{\circ} \mathrm{C}\right)$ and frozen at $-20^{\circ} \mathrm{C}$. After $3 \mathrm{~h}$ the sample was defrosted, and the supernatant was removed by decantation. Two volumes of ice-cold acetonitrile $\left(-20^{\circ} \mathrm{C}\right)$ were added to the precipitate, the mixture was frozen at $-20^{\circ} \mathrm{C}$, and let to stand at that temperature for $3 \mathrm{~h}$, after which it was defrosted, and the methanol and acetonitrile extracts were combined and reduced to dryness under nitrogen. The dry residue was dissolved in $1.5 \mathrm{~cm}^{3}$ of a buffer with $\mathrm{pH} 4.5$. Further analysis was performed like with urine.

The linear range of the developed procedure is $10.0-100.0 \mathrm{ng} / \mathrm{ml}$; the linear regression equation is $y=0.0112 x(n=3)$, correlation coefficient $R^{2}=0.995$. Analysis time was $8 \mathrm{~h}$.

\section{Results and discussion}

The literature concerning sensitive detection of CVAA in biomedical samples is fairly scarce $[6,8-10$, $12,14,15]$. In these works the acid was derivatized with vicinal dithiols (ethane-1,2-dithiol, propane1,3-dithiol or 1,2-dimercaptopropan-1-ol) to form volatile cyclic disulfides, which were detected by GC/EI-MS.

Vilensky et al. [11] suggested a procedure for the determination of CVAA and its oxidized form CVAOA in urine by HPLC/ICP-MS. The linear range of the procedure was three orders of magnitude, and the detection limits of CVAA and CVAOA were 1.4 and $1.3 \mathrm{ng} / \mathrm{ml}$, respectively.

Wooten et al. [15] analyzed CVAA after derivatization with propane-1,3-dithiol directly in aqueous samples (including urine), and the resulting volatile cyclic disulfide was detected by SPME combined with GC-MS in the SIM mode. The detection limit of CVAA was $7.4 \mathrm{pg} / \mathrm{ml}$ urine. However, the procedure was not tested on samples from in vivo experiments, which did not allow evaluation of its feasibility for the determination of CVAA in the conjugated form. We modified this procedure and applied it to the 
analysis of urine samples obtained in experiments in vivo. The procedure was also adapted to the analysis of blood plasma and red blood cells. The detection limits of CVAA in urine, blood plasma and red blood cells were $0.1,1.0$ and $10 \mathrm{ng} / \mathrm{ml}$, respectively.

\subsection{Effect of antidotal therapy with unithiol on the detection and identification of CVAA in biomedical samples}

An arsenic metabolic complex with unithiol was found in the urine of victims of poisoning with a high dose of arsenic in drinking water (up to $16 \mu \mathrm{g} / \mathrm{l}$ ) [7]. Urine samples were taken before and after oral administration of $300 \mathrm{mg}$ of unithiol. In the urine samples of victims treated with unithiol, a complex of unithiol with monomethylarsonous acid $\left(\mathrm{MMA}^{\mathrm{III}}\right)$. The unithiol treatment decreased the content of dimethylarsinic acid $\left(\mathrm{DMA}^{\mathrm{V}}\right)$ and increased the content of monomethylarsonic acid $\left(\mathrm{MMA}^{\mathrm{V}}\right)$. According to Gong et al. [7], MMA ${ }^{\mathrm{III}}$ is a substrate for biomethylation of arsenic in $\mathrm{MMA}^{\mathrm{V}}$ to form $\mathrm{DMA}^{\mathrm{V}}$; the formation of the unithiol-MMA ${ }^{\mathrm{III}}$ complex reduces the bioavailability of MMA ${ }^{\mathrm{III}}$ for the subsequent biomethylation and favors inhibition of arsenic methylation. As applied to lewisite, even though the effect of dithiol antidotal therapy is well established, its mechanism has still not been unambiguously interpreted.

To explore the effect of antidotes on the determination of CVAA in biomedical samples, we have analyzed three blank $1 \mathrm{ml}$ urine samples spiked with $100 \mathrm{ng}$ of CVAA. Two samples were treated with antidotes (one with BAL and the other with unithiol, each $1000 \mathrm{ng} / \mathrm{sample}$ ). Since we failed to detect the CVAA-unithiol complex in the biomedical samples from animals exposed to lewisite and further treated with unithiol, it was not unreasonable to suggest that unithiol largely fulfills a transport function here, by driving CVAA excretion. In this case, the presence of excess unithiol in urine would not prevent derivatization of CVAA with the stronger chelating agent PDT and, therefore, would not interfere with its determination. This suggestion, however, was ruled out by the results of our experiment (Table 1), which showed that a large excess of unithiol (which corresponds to conditions of antidotal therapy) binds CVAA and interferes with its determination. As seen from Table 1, in the presence of unithiol or BAL much smaller peaks of the CVAA and PAO derivatives were registered than in the absence of antidotes. Consequently, excess antidotes greatly decreased the yields of the derivatization with PDT for both CVAA and PAO.

Studying in vivo urine samples from group B animals we established, from decreased peak area of the internal standard PAO, that unithiol introduced $30 \mathrm{~min}$ after exposure to lewisite was actively excreted from the body within $3 \mathrm{~h}$. Simultaneous rapid excretion of the lewisite metabolite was also observed (Fig. 1). In the presence of high concentrations of unithiol quantitation of CVAA is problematic; no more than a rough estimate can be achieved. It is noted that in the analysis of the urine sample taken

Table 1

Effect of excess antidotes in urine on the determination of CVAA

\begin{tabular}{|c|c|c|c|c|c|c|}
\hline \multirow[t]{2}{*}{ Analyte } & \multicolumn{2}{|c|}{ No antidote added $(n=2)$} & \multicolumn{2}{|c|}{ BAL added $(n=2)$} & \multicolumn{2}{|c|}{ Unithiol added $(n=2)$} \\
\hline & $S$ & $C_{\text {estimated }}(\mathrm{ng})$ & $S$ & $C_{\text {estimated }}(\mathrm{ng})$ & $S$ & $C_{\text {estimated }}(\mathrm{ng})$ \\
\hline CVAA-PDT & $1,340,883$ & 92 & 17,685 & 47 & 46,396 & 49 \\
\hline PAO-PDT & 876,805 & 92 & 22,720 & 47 & 56,485 & 49 \\
\hline
\end{tabular}

Notes: $S$ is the analyte peak area, $C_{\text {estimated }}$ is the CVAA content estimated by the internal standard (PAO) method. 


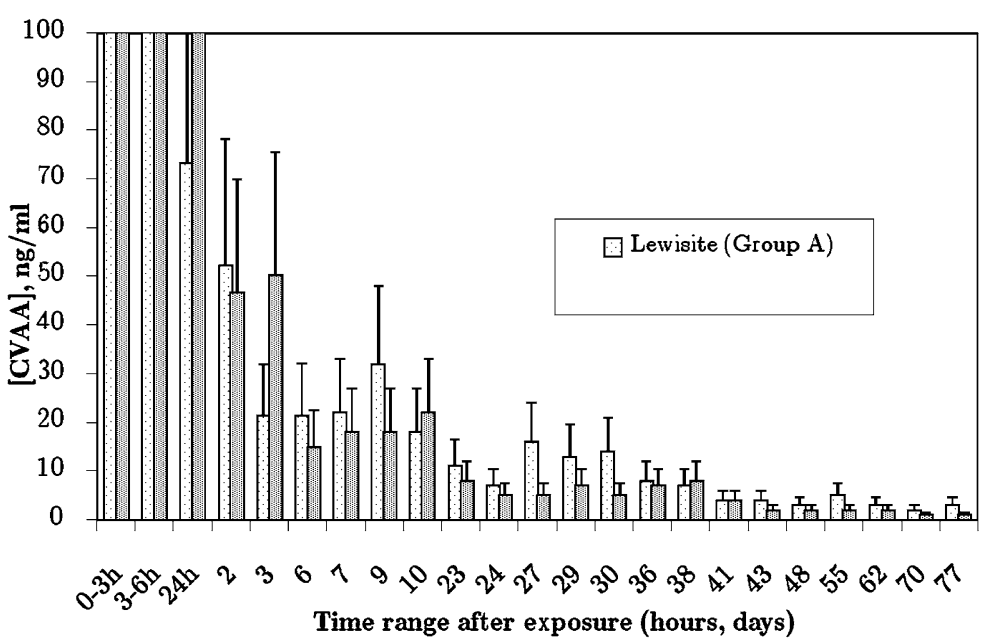

Fig. 1. Changes of CVAA levels in urine samples from group A and B animals. Bars are standard deviations based on 12 animals per group.

$24 \mathrm{~h}$ after unithiol treatment we observed no decrease of the PAO peak area, which implied no effect of unithiol on the determination of CVAA and PAO in urine.

Our study established the necessity for using PAO to reveal the presence of antidotes in urine; it functions to prevent false negative results concerning the exposure of an organism to lewisite. In cases where the peak area of the internal standard is below a preset threshold value, and thus the peak area of the CVAA derivative is very low or zero, unambiguous conclusions as to the exposure are avoided. Sampling should be repeated $24 \mathrm{~h}$ after antidotal treatment.

\subsection{Determination of CVAA in biomedical samples obtained in in vivo experiments}

The developed procedures allowed detection of CVAA in rat urine three months after, and in red blood cells 7 days after, intoxication with lewisite at a dose of $1.6 \mathrm{mg} / \mathrm{kg}$. The analytical error is no higher than $50 \%$, which gives us reasons to consider these procedures as semi-quantitative. Figures 2 and 3 show SPME-GC-MS determination of CVAA as 2-(2-chlorovinyl)-1,3,2-dithiarsenane in urine $24 \mathrm{~h}$ and 31 days after exposure to lewisite, respectively. Figure 1 illustrates changes in the urine CVAA levels after single subcutaneous injection of a solution of lewisite at a dose of $1.6 \mathrm{mg} / \mathrm{kg}$, with and without unithiol treatment (animal groups A and B, respectively).

The CVAA excretion profiles with and without antidotal therapy over the first day after lewisite exposure are quite different (Fig. 1). The highest concentration of CVAA $(c=30 \mu \mathrm{g} / \mathrm{ml})$ was detected within 3-6 h, after intoxication followed by unithiol treatment. In the absence of unithiol treatment, the estimated concentration of CVAA in urine within 3-6 h after intoxication was around $2.5 \mu \mathrm{g} / \mathrm{ml}$. A day after intoxication, the CVAA concentration in the urine samples of animals treated with unithiol was at least 5 -fold higher compared with animals not treated with the antidote. Beginning at $48 \mathrm{~h}$ after intoxication, no significant differences in the CVAA levels in the urine samples obtained from treated and untreated animals were observed.

Figures 4 and 5 show changes in CVAA concentrations in blood plasma and red blood cells, respectively, for group A and B animals. The concentrations of the lewisite metabolite in blood plasma and red blood cells from the group A and B animals $48 \mathrm{~h}$ after exposure were 6 and $150 \mathrm{ng} / \mathrm{ml}$, respectively. After 7 days the blood plasma levels of CVAA in both groups of animals were close to the detection 


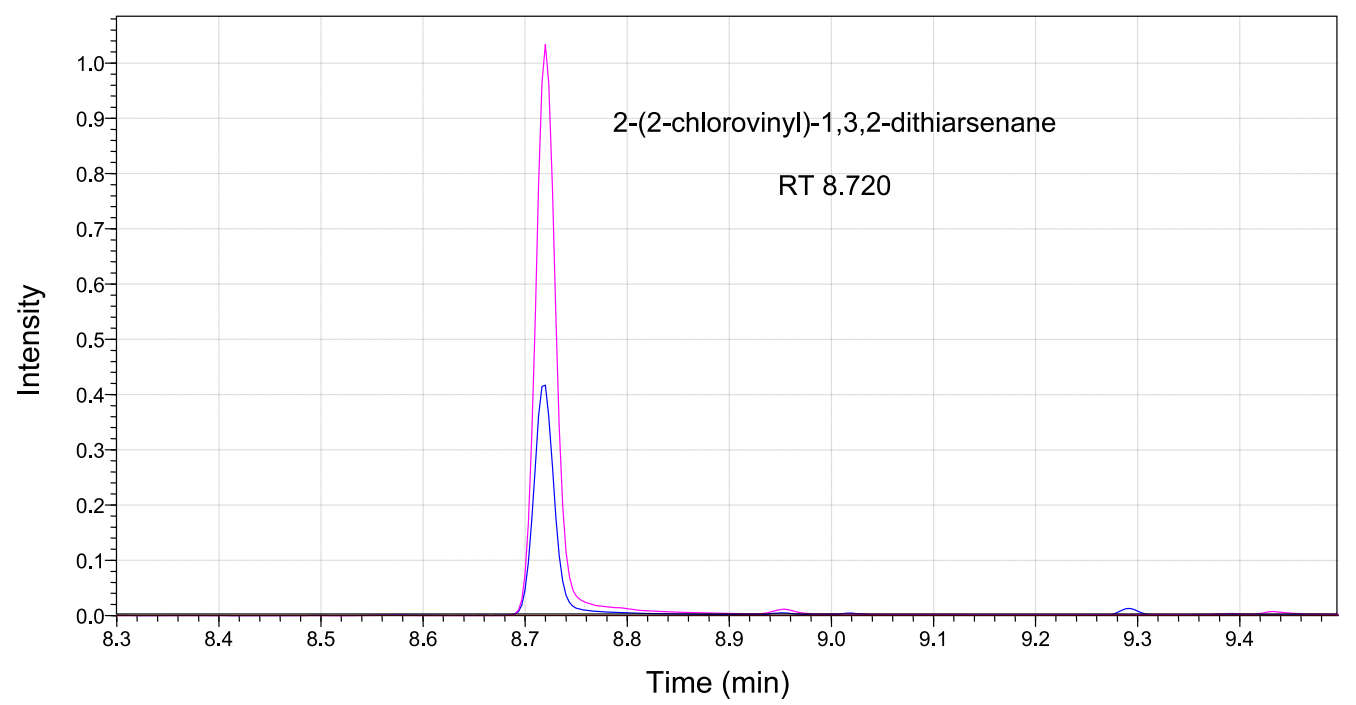

(a)

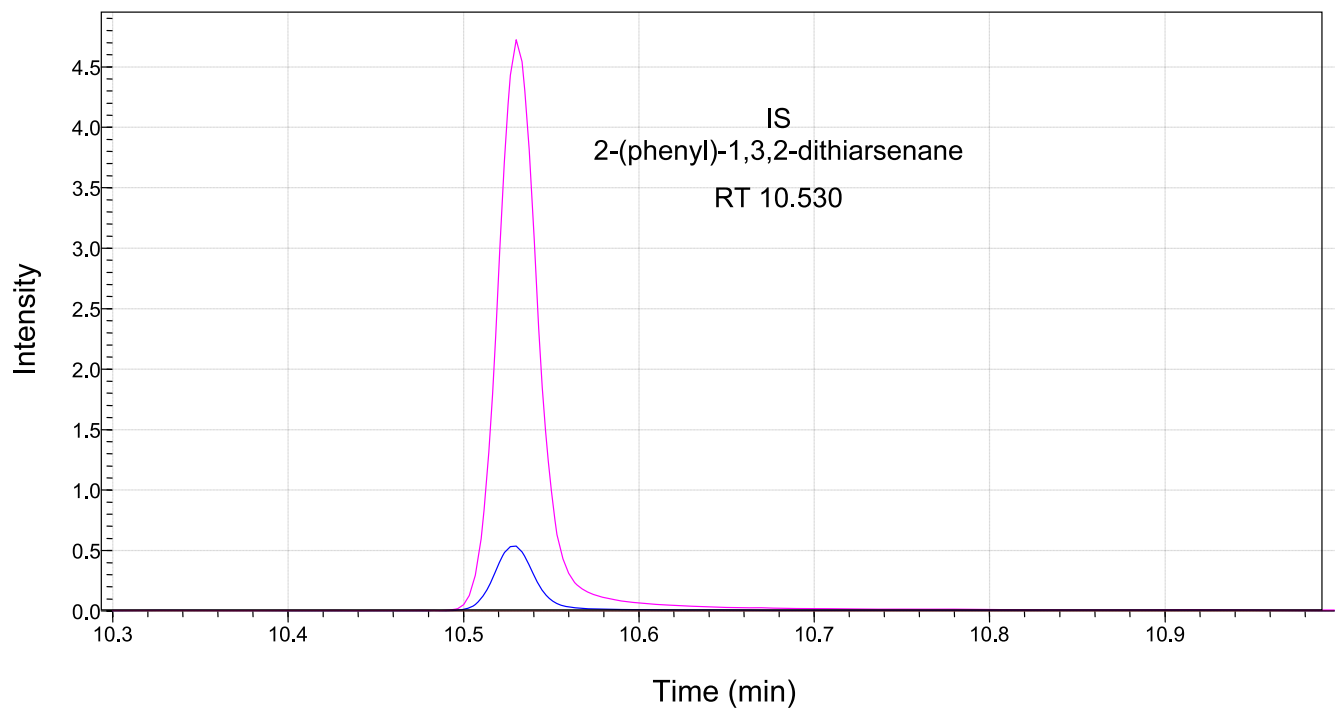

(b)

Fig. 2. SPME-GC-MS determination of CVAA as 2-(2-chlorovinyl)-1,3,2-dithiarsenane in urine $24 \mathrm{~h}$ after exposure to lewisite: (a) registration of the metabolite; (b) registration of inner standard (IS). (Colors are visible in the online version of the article; http://dx.doi.org/10.3233/SPE-2011-0514.)

limit $(c=1 \mathrm{ng} / \mathrm{ml})$, whereas in red blood cells of rats not treated with unithiol no decrease of the CVAA level was observed. These findings agree with the results of Fidder et al. [6], who reported GC-MS determination of CVAA at a $40 \mathrm{fmol}$ level in urine and whole blood of guinea pigs exposed to lewisite at a dose of $0.25 \mathrm{mg} / \mathrm{kg}$, after consecutive treatment with BAL heptabutyrylimidazole. In urine samples, CVAA was detected over the first $12 \mathrm{~h}$ after exposure, and in whole blood over ten days [6]. In vitro experiments on blood samples exposed to $\left[{ }^{14} \mathrm{C}\right]$-lewisite $(20 \mathrm{nM}-0.2 \mathrm{mM})$ showed that more than $90 \%$ of radioactivity was concentrated in red blood cells, with $25-50 \%$ bound to globine [6]. 


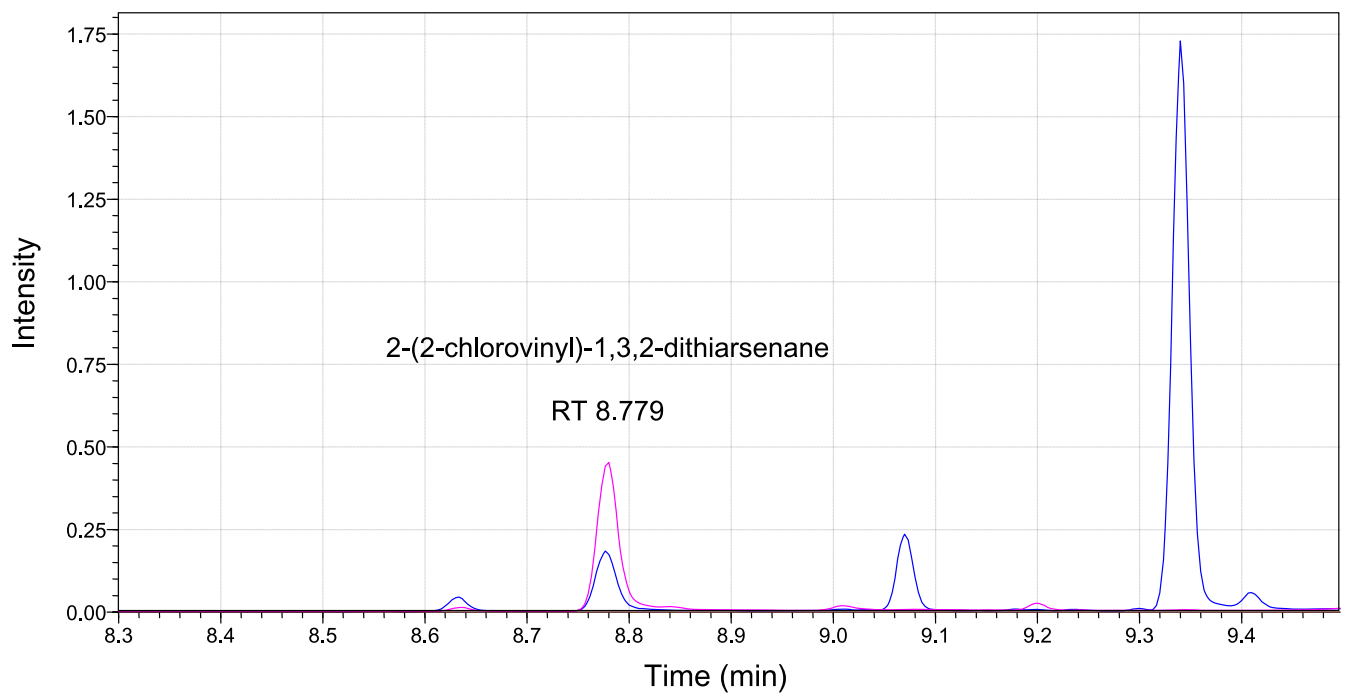

(a)

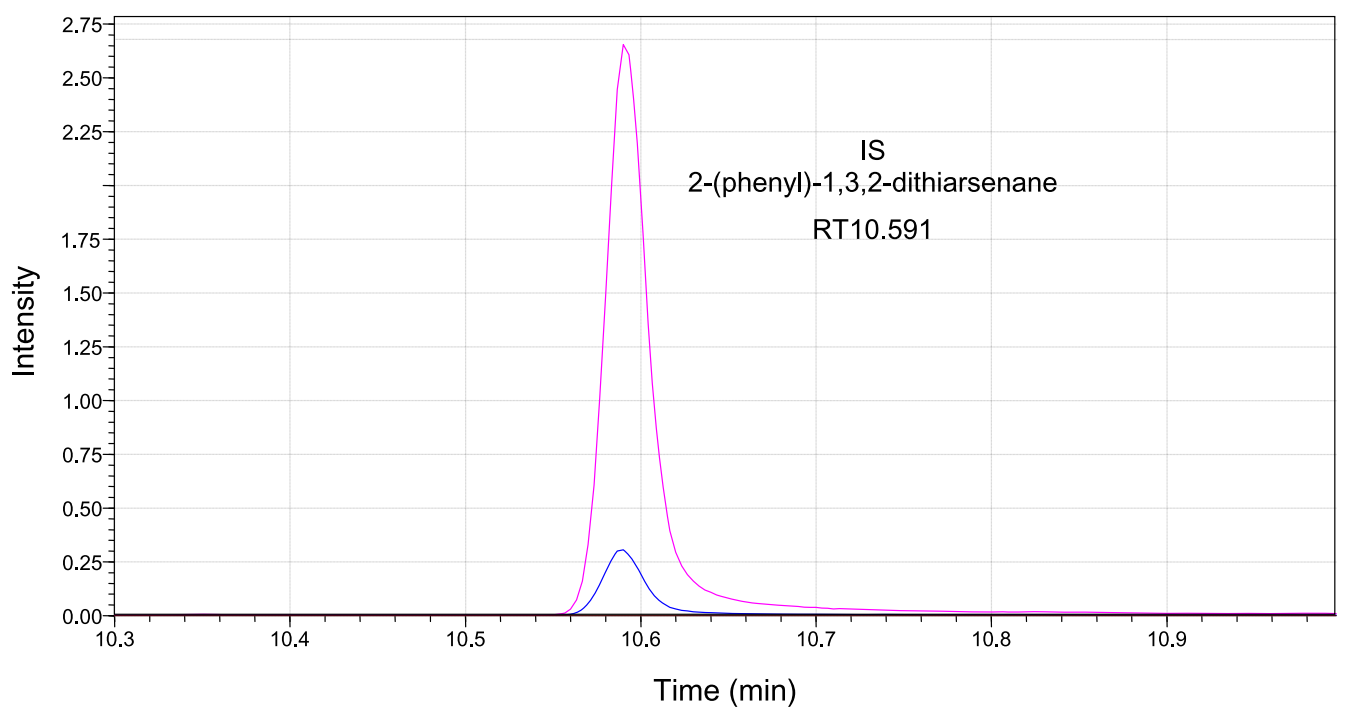

(b)

Fig. 3. SPME-GC-MS determination of CVAA as 2-(2-chlorovinyl)-1,3,2-dithiarsenane in urine 31 days after exposure to lewisite: (a) registration of the metabolite; (b) registration of inner standard (IS). (Colors are visible in the online version of the article; http://dx.doi.org/10.3233/SPE-2011-0514.)

We plan to proceed with investigation of samples obtained in the above animal experiments, with the aims of assessing the sensitivity of CVAA analysis for red blood cells and establishing the form of CVAA in biomedical samples under the conditions of antidotal therapy. In the present work we synthesized a lewisite-unithiol complex and could characterize it by chromatographic and spectral data, but failed to detect it biomedical samples. Even though the mechanism of the antidotal activity of unithiol against lewisite seems fairly simple, at present we do not have a clear understanding of the active excretion of lewisite and its redistribution from tissues to bloodstream. 


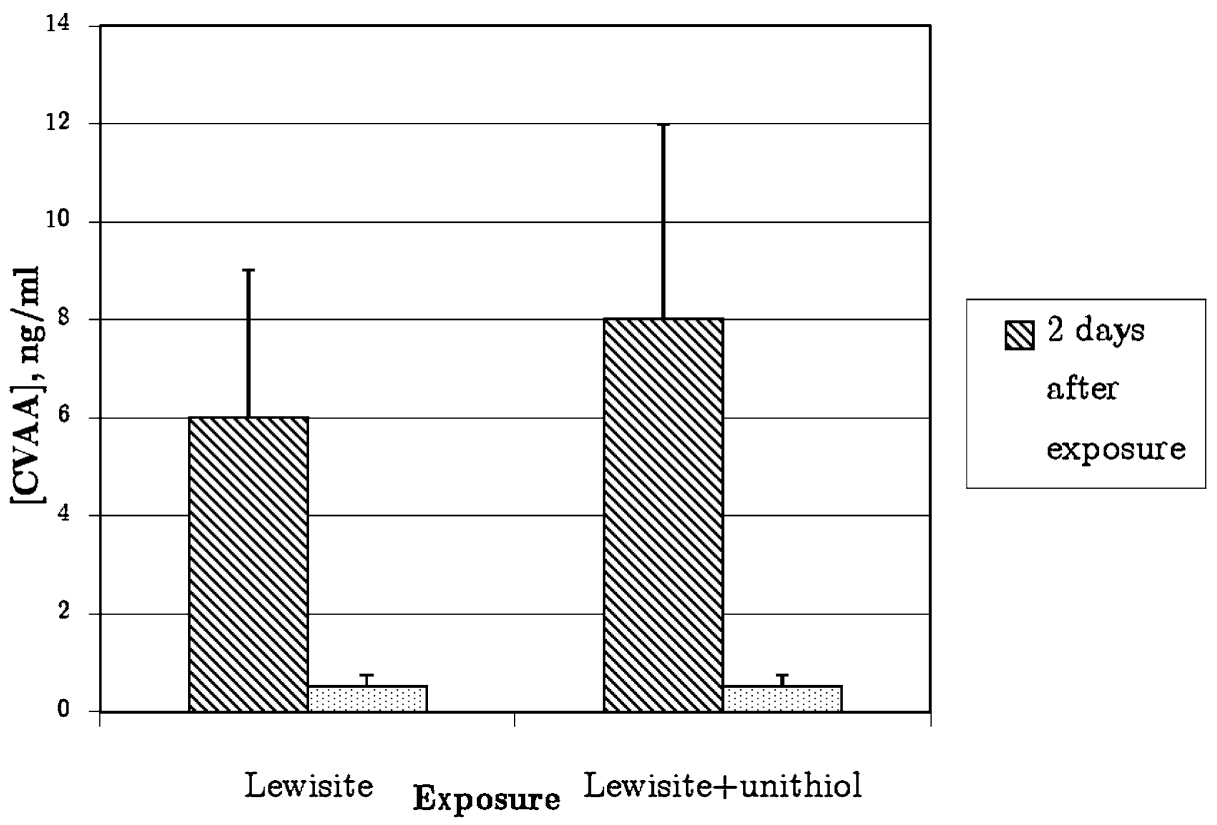

Fig. 4. Changes in the CVAA concentrations in blood plasma from group A and B animals. Bars are standard deviations based on 12 animals per group.

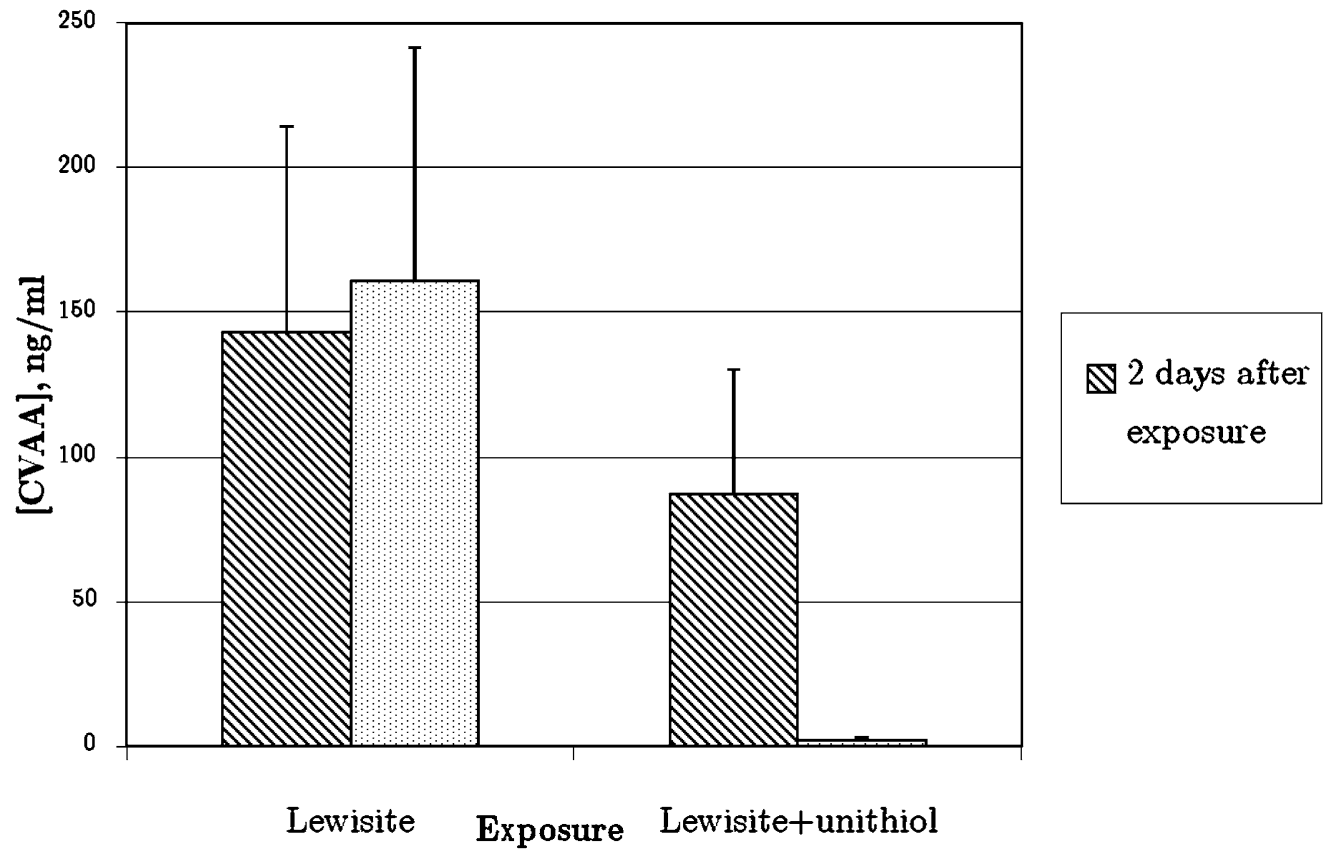

Fig. 5. Changes in the CVAA concentrations in red blood cells from group A and B animals. Bars are standard deviations based on 12 animals per group. 


\section{Conclusion}

Our toxicological experiment (exposure of animals to lewisite with and without antidotal therapy) showed that urine is a universal and preferential matrix for the determination of lewisite biomarkers. Blood (red blood cells) is a perspective matrix for confirmation of the results of urine analysis. Conversely, blood plasma is considered a non-perspective matrix in terms of establishment of exposure to lewisite, since the blood plasma levels of the biomarker are relatively low. It was found that the antidotal therapy with unithiol considerably affects the CVAA excretion profile within the first day after antidotal treatment. Antidotal therapy increases the possibility of CVAA detection in urine within two days after the introduction of unithiol. In addition, the lewisite biomarker can be detected in urine samples for relatively long periods after exposure.

\section{References}

[1] H.V. Aposhian, DMSA and DMPSs water soluble antidotes for heavy metal poisoning, Annu. Rev. Pharmacol. Toxicol. 23 (1983), 193-215.

[2] H.V. Aposhian, D.E. Carter, T.D. Hoover et al., DMSA, DMPS, and DMPAs as arsenic antidotes, Fundam. Appl. Toxicol. 40 (1984), S58-S70.

[3] H.V. Aposhian, R.M. Maiorino, D. Gonzalez-Ramirez et al., Mobilization of heavy metals by newer, therapeutically useful chelating agents, Toxicology 97 (1995), 23-38.

[4] Convention on the Prohibition of the Development, Production, stockpiling and use of chemical weapons and on their destruction, UN, New York, 1993.

[5] European Convention for the Protection of Vertebrate Animals Used for Experimental and other Scientific Purposes, ETS No. 123, Strasbourg, 1986.

[6] A. Fidder, D. Noortand Hulst et al., Biomonitoring of exposure to lewisite based on adducts to haemoglobin, Arch. Toxicol. 74 (2000), 207-214.

[7] Z. Gong, G. Jiang and W. Cullen, Determination of arsenic metabolic complex excreted in human urine after administration of sodium 2,3-dimercapto-1-propane sulfonate, Chem. Res. Toxicol. 15 (2002), 1318-1323.

[8] E. Jakubowski, J. Smith and T. Logan, Verification of lewisite exposure: quantification of chlorovinylarsonous acid in biological samples, in: Proceedings of the 1993 Medical Defense Bioscience Review, US Army Medical Research Institute of Chemical Defense, Aberdeen Proving Ground, MD, USA, 1993, pp. 728-731, AD A275667.

[9] T. Logan, J. Smith, E. Jakubowski and R. Nielson, Verification of lewisite exposure by the analysis of 2-chlorovinyl arsonous acid in urine, Toxicol. Meth. 9 (1999), 275-284.

[10] J. Smith, T. Logan, L. Szafraniec and E.M. Jakubowski, Spectroscopic characterization of the geminal isomer of lewisite, Anal. Lett. 28 (1995), 1541-1554.

[11] R. Stanelle, W. McShane, E. Dodova and R. Pappas, Rapid analysis of lewisite metabolites in urine by high-performance liquid chromatography-inductively coupled plasma-mass spectrometry, J. Anal. Toxicol. 4 (2010), 122-128.

[12] S.D. Tuorinsky (ed.), Medical aspects of chemical warfare, in: Medical Diagnostics, Library of Congress, Washington, DC, USA, 1997, pp. 728-731, Chapter 22.

[13] J.A. Vilensky and K. Redman, British anti-lewisite (Dimercaprol): an amazing history, Ann. Emerg. Med. 41 (2003), 378-383.

[14] W. Waters and J. Williams, Hydrolyses and derivatives of some vesicant arsenicals, J. Chem. Soc. (1950), 18-22.

[15] J. Wooten, D. Ashleyand and A. Calafat, Quantitation of 2-chlorovinylarsonous acid in human urine by automated solidphase microextraction-gas chromatography-mass spectrometry, J. Chromatography B: Anal. Technol. Biomed. Life Sci. 772 (2002), 147-153. 


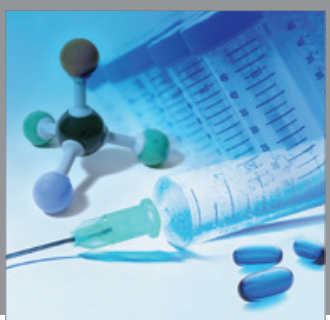

International Journal of

Medicinal Chemistry

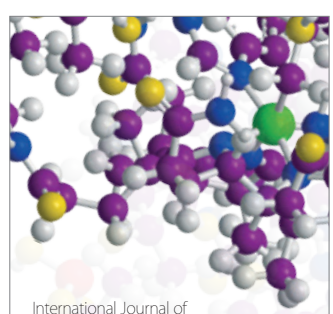

Carbohydrate Chemistry

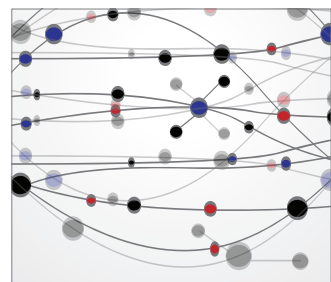

The Scientific World Journal
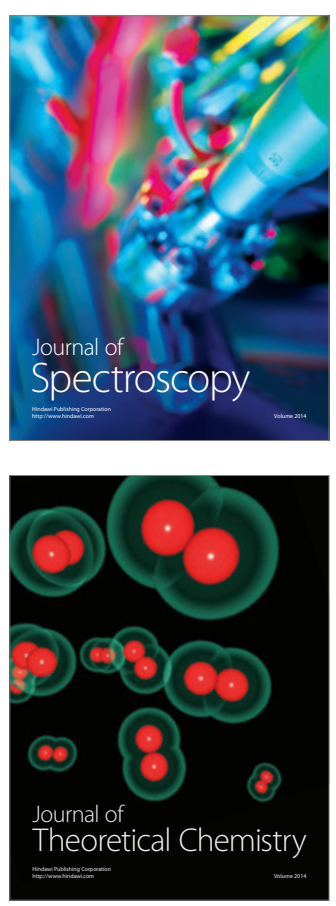
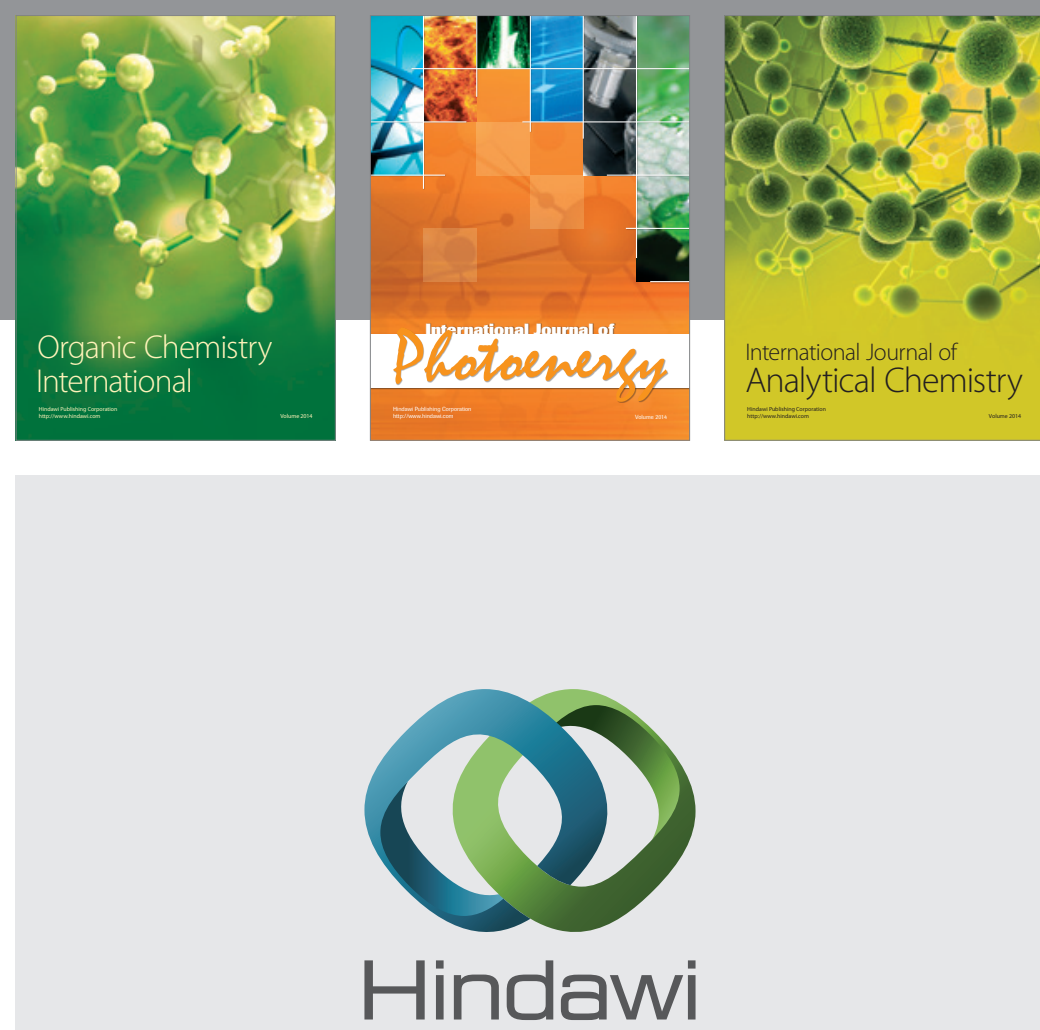

Submit your manuscripts at

http://www.hindawi.com
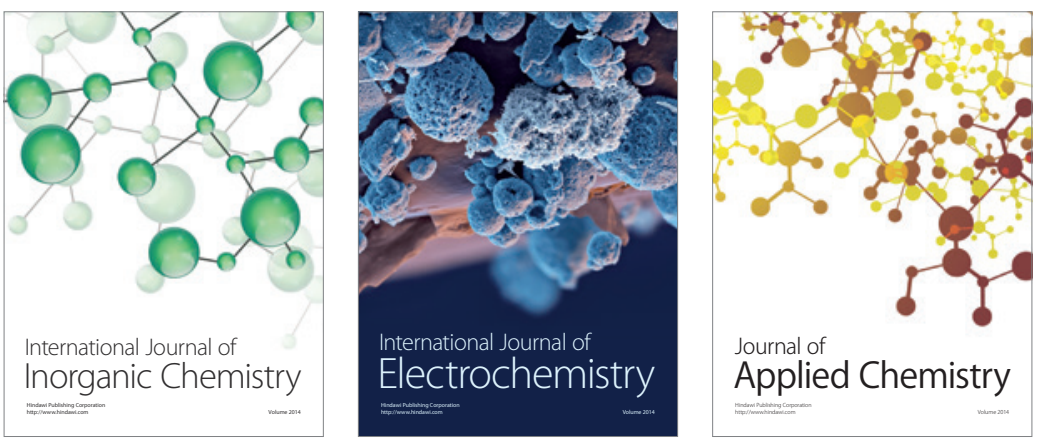

Journal of

Applied Chemistry
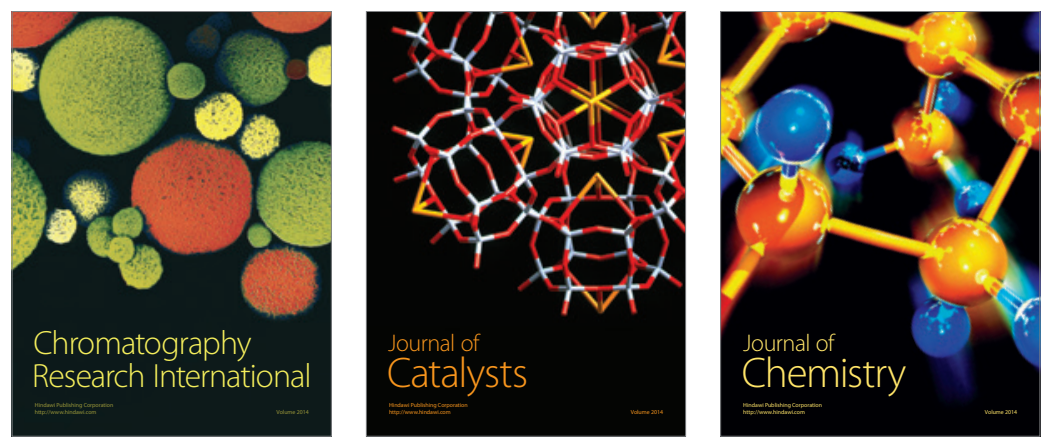
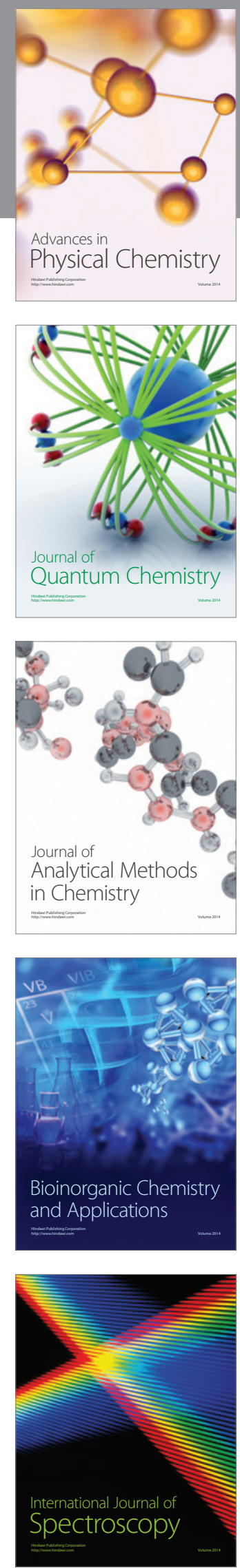